\title{
O EMPREENDEDOR E A APLICAÇÃO DO SISTEMA DE CUSTEIO-ALVO EM PEQUENA EMPRESA DO SEGMENTO DE PLÁSTICO: UMA PESQUISA-AÇÃO ${ }^{1}$
}

\author{
THE ENTREPRENEUR AND THE APPLICATION OF THE SYSTEM OF TARGET \\ COSTING IN SMALL BUSINESS OF THE PLASTIC SEGMENT: AN ACTION- \\ RESEARC
}

\author{
Ana Cristina de Faria $^{2}$ \\ Luiz Henrique de Freitas ${ }^{3}$ \\ José Carlos Marion ${ }^{4}$
}

\begin{abstract}
RESUMO: As micros e pequenas empresas (MPE's) exercem papel fundamental na economia nacional; porém, há muitas dificuldades para se manterem ativas no mercado por longos períodos de tempo. Este trabalho enfatizou o perfil do empreendedor e a situação atual da MPE no Brasil. Um dos problemas destas empresas é a maneira de gerir (ou não) seus custos, levando-as, por vezes, a obter prejuízos em suas operações. O objetivo deste estudo é verificar, por meio de uma pesquisa-ação, se o Sistema do Custeio-Alvo gera informações econômico-financeiras úteis e oportunas, é um instrumento inovador à gestão de custos e resultados do empreendedor de um pequeno negócio. Para desenvolver a pesquisa, buscou-se um pequeno negócio administrado por empreendedores que, com foco na gestão de seus custos, concordassem em envolver-se ativamente na pesquisa, de modo cooperativo e participativo, tal como preconiza a metodologia empregada. As informações apuradas a partir da aplicação do Sistema do Custeio-Alvo na empresa analisada, que contemplaram os valores dos custos máximos a serem incorridos em cada produto, bem como a necessidade de redução para atingir o alvo, foram consideradas pelos sócio-empreeendedores como úteis e oportunas; pois são de fácil apuração e interpretação, e de caráter inovador e estratégico à gestão do pequeno negócio.
\end{abstract}

Palavras-chave: Custeio Alvo; Custo-Alvo; Empreendedor; Pesquisa-ação.

ABSTRACT:Small business (SB's) perform key role in national economy, but there are many difficulties to remain active in the market for long periods of time. This work emphasized the profile of the entrepreneur and the current status of SB in Brazil. One of the problems of these companies is how to manage (or not) costs, leading them sometimes to obtain damages in its operations. The aim was to verify, through action research, if the System of Target Costing generates economic and financial information timely and useful, is an innovative instrument for the management of costs and results of a small business' entrepreneur. To develop the research, we tried to a small business run by entrepreneurs who, with a focus on managing its costs, agree to actively get involved in the research, cooperative and participatory as advocates for the methodology used. The information cleared from the application of the System of Target Costing in the company examined, which covered the values of the maximum cost to be incurred in each product and the need for reductions to achieve the target, were considered by partner-entrepreneurs as useful and timely because it is easy to investigation and interpretation, and innovative and strategic management of small business.

Key-Words: Target Cost; Target Costing; Entrepreneur; Action-Research.

\footnotetext{
${ }^{1}$ Artigo Recebido em 10.10.2008. Revisado por pares em 05.02.2009. Recomendado em 14.07.2009 por Leomar dos Santos (Editor Adjunto). Publicado em 03.09.2009.

Organização Responsável pelo periódico: Universidade regional de Blumenau - FURB - www.furb.br/rn

${ }^{2}$ Universidade Municipal de São Caetano do Sul - anacfaria@imes.edu.br

${ }^{3}$ Mackenzie - luizhenrique@mackenzie.br

${ }^{4}$ Pontifícia Universidade Católica - PUCSP - jcmarion@usp.br
} 


\section{INTRODUÇÃO}

A internacionalização da economia e o conseqüente acirramento da concorrência, neste cenário globalizado, fazem com que as empresas busquem, ao máximo, implementar uma redução de seus custos, objetivando assim, uma maior competitividade para seus produtos. Segundo Monden (1999), este tipo de competição está se tornando cada vez mais árdua neste mercado global, fazendo com que as empresas passem a oferecer produtos com qualidade e que, ao mesmo tempo, agradem aos consumidores com preços mais acessíveis.

Em um mercado que se apresenta altamente competitivo, buscar melhorias nos processos internos e criar meios para se manter os gastos (custos e despesas) da empresa, devidamente controlados, pode significar a continuidade da mesma, e deve ser alvo permanente de uma boa gestão empresarial. Com o aumento da oferta de produtos, o mercado passou a determinar o preço a ser praticado pelas organizações e, nesse contexto, o gerenciamento adequado dos custos tornou-se uma vantagem competitiva relevante, independentemente do porte ou do segmento de atuação da empresa, na busca da otimização de seus resultados (MAXIMIANO, 2006).

Inovações tecnológicas, parcerias e alianças estratégicas com o objetivo de minimizar custos, bem como novas estratégias competitivas abundam em grandes corporações, que têm sido forçadas a implementar novas práticas de gestão para sobreviverem no mercado. No entanto, será que estas novas práticas têm sido utilizadas pelas micro e pequenas empresas (MPE's)?

No caso das micro e pequenas empresas (MPE's), esta questão se torna ainda mais fundamental. Na maioria das vezes, o empreendedor de uma MPE, carente de uma capacidade de gestão mais aprimorada, se vê em dificuldades no momento de determinar os verdadeiros custos de sua operação e, conseqüentemente, de determinar o preço de venda adequado de seu produto. Chér (1991, p. 42), com relação à importância do gerenciamento de custos para as pequenas e médias empresas (PME's) corrobora com esta idéia, e comenta que muitas empresas reclamam de problemas na gestão de seus custos, preços e resultados, e do quanto cada produto contribui para o resultado total da empresa, de maneira que o assunto apresenta relevância.

A perspectiva de fortalecimento da MPE, principalmente nos últimos anos, tem sido bastante discutida por diversos segmentos da economia brasileira. Em pesquisa realizada pelo Serviço Brasileiro de Apoio às Micro e Pequenas Empresas do Estado de São Paulo Sebrae-SP, organizada por Bedê (2005), identificou-se que as MPE's respondem por 99\% do total das empresas do país; $28 \%$ do faturamento do setor privado; $20 \%$ do PIB brasileiro e $2 \%$ do valor das exportações nacionais. Assim, os aspectos ora citados sobre este segmento empresarial e seus vínculos com a economia nacional, corroboram com a importância do assunto deste estudo.

Por meio do relatório denominado "Sobrevivência e Mortalidade das Empresas Paulistas de 1 a 5 anos" (edição 2005), que utilizou uma amostra aleatória de 2.000 empresas, representativa das unidades registradas na Junta Comercial do Estado de São Paulo - Jucesp no período de 1999 a 2003, pode-se identificar que a taxa de mortalidade é de $29 \%$ para empresas até um ano; e que, em torno de $56 \%$ dos empreendimentos não concluem o quinto ano de atividade (BEDÊ, 2005).

Apesar desta redução apresentada, a mortalidade precoce dos pequenos negócios ainda continua em patamares elevados, e tem como causas diversos fatores; dentre estes: a implementação de um planejamento adequado e a escolha da melhor opção para obtenção de recursos financeiros encontra-se sob o controle do empreendedor. Outros, por sua vez, de 
cunho conjuntural, independem da sua atuação, tais como: a retração do mercado consumidor, o acirramento da concorrência e a implementação de uma expressiva carga tributária resultante da adoção de políticas econômicas governamentais.

As micro e as empresas de pequeno porte (EPP), em sua maioria, na opinião de Kassai (1996) e Pinheiro (1996), padecem de problemas estruturais e, dentre eles, encontramse aqueles relacionados à gestão do negócio que é exercida de forma personalista pelo seu proprietário. Conforme Neck (2000), isso ocorre, também em outros países, tais como: Argélia, Austrália etc. Geralmente, as principais decisões sobre o negócio estão centralizadas em seu dirigente maior, o empreendedor, que desprovido de um conhecimento técnico mais apurado, utiliza-se do seu feeling para nortear os rumos de sua empresa. Matias e Lopes Júnior (2002, p. 6), concordam com esta análise ao comentarem os pontos fracos das EPP's, afirmando que "a administração das pequenas empresas está nas mãos de poucas pessoas, sendo que muitos desconhecem princípios de administração e instrumentos básicos de gestão, o que facilita muito que aquele perfil de empreendedor e suas características não sejam encontrados, causando a 'morte' da pequena empresa."

Como já comentado, neste segmento empresarial, a gestão encontra-se centralizada na figura do proprietário-empreendedor, o qual, na maioria das vezes, não se apresenta preparado tecnicamente para implementá-la de maneira adequada. Estes empreendedores, conduzidos por sua motivação em realizar, muitas vezes, administram seus negócios desde a sua concepção até a sua implementação em bases intuitivas, sujeitando-se a riscos que, normalmente, os conduzem à descontinuidade de suas empresas. Para Machado (2005, p. 24), "o verdadeiro empresário é aquele que faz acontecer. Muitos têm boas idéias, mas, daí a transformá-las em realizações, existe uma distância muito grande." Assim, por vezes, o empreendedor constitui a sua empresa sem perceber que, a partir daquele momento, será ele quem conduzirá o destino de seu negócio.

No caso específico do pequeno negócio, pode-se considerar que o proprietáriogestor, sem o conhecimento técnico necessário, por vezes, determina o seu preço de venda tomando como base o preço praticado pela concorrência, sem utilizar para tal, uma análise apurada dos custos incorridos durante o processo produtivo. Ou ainda, adiciona simplesmente uma margem (mark-up) de algumas vezes o valor de sua matéria-prima (no caso de uma empresa industrial), estabelecendo, assim, o preço de venda a ser praticado no mercado.

Na opinião de Chér (1991, p. 42), "a despeito de sua importância, a contabilização dos custos nas MPE's não tem sido praticada, na maioria das vezes." E complementa que, "na medida em que grande parte das MPE's reclama de seus custos, da falta de controle sobre os mesmos, da dificuldade em precificar os produtos e do desconhecimento que possuem em relação à contribuição destes produtos para o lucro total, este assunto se torna tema de suma relevância".

A não utilização de informações estruturadas sobre os custos da empresa, e a concomitante aplicação do índice mark-up como sendo a única base da determinação do preço de venda, poderá conduzir o empreendedor a praticar preços incompatíveis com o seu mercado de atuação, deixando a empresa sem condições de competir com a concorrência. Por outro lado, utilizar-se apenas do preço praticado pela concorrência como base para precificar os seus produtos, sem observar todos os custos inerentes ao processo produtivo e as despesas de operacionalização do negócio, é correr o risco de, quanto mais vender, mais incorrer em resultados negativos.

Assim, neste novo contexto, não se cogita a determinação do custo unitário total como sendo a principal condicionante para a fixação do preço de venda, sendo o mercado quem, de fato, o determina. Dessa forma, invertendo uma situação observada anteriormente, na qual, o custo da produção de um bem determinava o seu preço de venda, utiliza-se o seu 
preço de venda para determinar o custo máximo que a empresa poderá admitir sem prejuízos para os seus resultados. Esta é a filosofia do sistema de custeio chamado de custeio-alvo ou custeio-meta (target costing).

Estes pontos fundamentam os aspectos gerais da situação-problema a ser tratada durante este estudo. Considerando ser o assunto "gestão de custos" um tema bastante abrangente, será tratada a gestão de custos da MPE por meio da formulação da seguinte questão de pesquisa: O Sistema do Custeio-Alvo gera informações econômico-financeiras úteis e oportunas, e é um instrumento inovador, para a gestão de custos e resultados do empreendedor de um pequeno negócio?

Para responder a esta questão, o objetivo geral deste estudo é verificar, por meio de uma pesquisa-ação, se o sistema do custeio-alvo gera informações econômico-financeiras úteis e oportunas, e é um instrumento inovador à gestão de custos e resultados do empreendedor de um pequeno negócio.

No intuito de responder à questão norteadora deste artigo, bem como atingir ao objetivo definido, além desta Introdução, o texto está organizado em mais seis tópicos: $\mathrm{O}$ Empreendedor e a Micro e Pequena Empresa - em que aborda o perfil do empreendedor e a necessidade de melhorias na gestão da MPE; O Sistema do Custeio Alvo (Target Costing) em que será abordado este instrumento a ser utilizado na gestão dos custos de uma MPE; Aspectos Metodológicos - em que está explicitada a metodologia de pesquisa adotada no desenvolvimento deste trabalho; A Aplicação do Custeio Alvo na Pequena Empresa Alfa em que será desenvolvida a pesquisa-ação; as Conclusões sobre a trabalho e Recomendações para futuras pesquisas, bem como as Referências que permeiam este artigo.

\section{O EMPREENDEDOR E A MICRO E PEQUENA EMPRESA (MPE)}

Os desafios impostos pelo mercado de trabalho e as novas formas de relações existentes entre o empregado e o empregador fazem do empreendedorismo um assunto bastante atual. Dornelas (2001, p. 37) citando Schumpeter, comenta que, "o empreendedor é aquele que destrói a ordem econômica existente pela introdução de novos produtos e serviços, pela criação de novas formas de organização ou pela exploração de novos recursos materiais." Originário da palavra francesa "entrepreneur", o vocábulo empreendedor significa aquele que assume riscos e começa algo novo.

O empreendedor, na opinião de Bernardi (2003), é a pessoa que inicia e opera um negócio para realizar uma idéia ou projeto pessoal assumindo riscos e responsabilidades. Dessa forma, espera, intuitivamente e na maioria das vezes, que seus esforços de tempo e de investimentos financeiros sejam recompensados por meio de resultados (lucros), e que estes retornos cubram, principalmente, os riscos e a iniciativa que assumiram ao operar seus próprios negócios. Outras, em busca de uma maior experiência, ou visando a acumular o capital necessário para o início de um empreendimento, aceitam a situação de serem empregadas, até o momento em que se sentem seguras o suficiente para se lançarem a um negócio próprio, podendo tomar decisões, assumir riscos e colher os retornos destes investimentos por si só.

Longenecker et al. (2003) comentam que um estereótipo comum do empreendedor ressalta características como uma grande necessidade de realização, ou seja, disposição para assumir riscos, por vezes moderados, e com forte autoconfiança. Segundo Dornelas (2001, p. 15), empreendedor é aquele que faz acontecer, que se antecipa aos fatos e tem uma visão futura da organização. Assim, para empreender é preciso ter a visão de futuro. As MPE's 
precisam ser geridas por empreendedores com este perfil, para que consigam manter sua continuidade.

Matias e Lopes Júnior (2002), ao considerarem os pontos fortes da empresa de pequeno porte, destacam a possibilidade de a mesma ser mais flexível do que as empresas médias ou grandes, por possuírem uma estrutura menor, pouca burocracia e um corpo administrativo reduzido. Estes aspectos facilitam a velocidade das decisões, a comunicação interna e as relações do empreendedor com seus funcionários, fornecedores, clientes e a comunidade. No entanto, estes autores, ao analisar os pontos fracos das pequenas empresas, comentam que a má gestão é a principal responsável pelo elevado índice de fracassos das mesmas.

Muitas vezes, despreparado tecnicamente, o pequeno empresário não consegue identificar o momento oportuno de promover as renovações necessárias; sendo que, quando as identifica, ou não se sente seguro para tais mudanças, ou arrisca-se a implementá-las de maneira desorganizada, apurando, muitas vezes, resultados negativos por conta desta improvisação, e que podem levar à descontinuidade do empreendimento.

Observando as causas dos insucessos apresentadas pela pesquisa do Sebrae-SP (2005), identifica-se que a maioria dos fatores precipitadores do insucesso dos negócios citados nas pesquisas, possui vínculo direto ou indireto com problemas de gestão, tais como: incompetência gerencial, inexperiência em gerenciamento, negligência nos negócios e ausência de planejamento prévio, vêm determinar a expressiva falta de habilidades administrativas e gerenciais do empreendedor. Destacam-se dificuldades ligadas ao modelo de gestão do empreendedor que, em alguns momentos, sente dificuldades em implementar uma gestão adequada para a sua empresa, costumando ser centralizador. Assim, assume a responsabilidade pela condução das mais diversas áreas da gestão empresarial, tais como: as compras, a produção, o marketing, as vendas, a distribuição dos produtos e serviços, o controle financeiro, as negociações com fornecedores, clientes e bancos, dentre outras atividades.

O principal problema consiste no fato de o empreendedor, sem preparo gerencial e, por vezes, sem buscar ter acesso às informações estratégicas necessárias a uma boa tomada de decisão, ver-se exposto à racionalidade limitada especificada por Chiavenato (2001), utilizando a sua intuição e a improvisação como seus principais recursos gerenciais; o que tendem a conduzi-lo a resultados poucos satisfatórios. Neck (2000) comenta que, o empreendedor deve aplicar enfoques mais inovadores para melhorar a gestão, e por sua vez, seus resultados.

No intuito de facilitar, em alguns aspectos, a gestão dos pequenos negócios, em 14.12.2006 foi sancionada a Lei Complementar $\mathrm{n}^{\mathrm{o}} 123$, denominada Lei Geral das Micro e Pequenas Empresas que passou a ser considerada a principal lei a, efetivamente, apresentar um tratamento diferenciado e simplificado às empresas de micro e pequeno porte. O conjunto de medidas aprovadas nesta Lei tem por finalidade promover a melhoria do ambiente empreendedor no Brasil, e aborda temas relacionados a várias situações de interesse do pequeno empresário. Dentre eles, destacam-se: a diminuição de sua carga tributária; maiores facilidades para acesso ao crédito; desburocratização e redução do prazo para o processo da abertura e encerramento das empresas; prioridade em compras governamentais de até $\mathrm{R} \$ 80$ mil; parcelamento das dívidas tributárias vencidas até $31.01 .06 \mathrm{em}$ até 120 meses, desde que a parcela seja de, no mínimo, $\mathrm{R} \$ 100,00$ (cem reais); acesso à inovação tecnológica; consórcio de empresas etc. Diante disso, o empreendedor das MPE's pode obter mais recursos para aprimorar suas operações, e otimizar sua gestão.

A Small Business Administration - SBA existente nos Estados Unidos da América (EUA) é uma entidade semelhante ao SEBRAE brasileiro. Em seu mais recente relatório "A 
Economia das Pequenas Empresas - um relatório para o Presidente", a SBA (2007), evidencia informações sobre a economia das pequenas empresas norte-americanas no ano de 2006, no que tange às aberturas ou fechamentos destas, dados operacionais, sociais, econômicos e financeiros. As informações sobre os custos destas empresas são destacadas em um dos tópicos, tendo como fonte primária dos dados, um censo realizado anualmente, o "U.S. Census Bureau Business Expenses Survey". Ou seja, existe nos EUA, uma pesquisa oficial sobre os custos das pequenas empresas, visando a buscar reduções e melhorias na gestão destes.

Nesse contexto, em que se buscam melhorias na gestão para a continuidade dos pequenos negócios, considera-se que a sobrevivência das MPE's está diretamente relacionada à sua capacidade de prever cenários favoráveis ou adversos, bem como em ser flexível para implementar mudanças rápidas de rumo para adaptar-se a novas realidades do mercado. Desta forma, as informações de custos e resultados econômicos apresentam-se como sendo de fundamental importância para orientar o empreendedor em suas decisões cotidianas. $\mathrm{Na}$ seqüência, será tratado sobre o Sistema do Custeio Alvo, um possível instrumento a ser utilizado na gestão dos custos dos pequenos negócios.

\section{O SISTEMA DO CUSTEIO ALVO (TARGET COSTING)}

A maioria dos pequenos empresários não possui a noção clara da importância da identificação, mensuração e controle de seus custos e, desta forma, estes, por vezes, pouco interfere na determinação do preço de venda dos seus produtos (SEBRAE, 2006). Se não há um controle eficiente dos custos das operações de uma empresa, de acordo com Bertó e Beulke (2006), o preço de venda de seus produtos é estabelecido de maneira rudimentar, muito mais voltado para uma análise dos preços praticados pela concorrência do que visando a cobrir os custos "ora desconhecidos", e agregando-os uma determinada margem de lucro (mark up).

Dubois et al. (2006) são da opinião de que quem mais se beneficia com a implantação de um bom sistema de gestão de custos são os próprios empresários, tendo em vista as avaliações que podem fazer acerca de seus investimentos. Não há como conduzir as atividades, de maneira adequada, se a alta administração não dispuser de informações precisas sobre os custos de produção e as despesas incorridas, que compõem os gastos totais da empresa.

O preço de venda, na maioria das vezes, é determinado pelo custo adicionado de uma margem de lucro pretendida, sendo que, nem sempre o preço corresponderá ao valor percebido pelo consumidor com relação ao produto oferecido pela empresa. Horngren, Datar e Foster $(2004$, p. 389), comentam que existem dois pontos de partida diferentes para as decisões de precificação, ou seja, um baseado no custo, também denominado de custo mais margem, e outro baseado no mercado. Portanto, enquanto algumas empresas observam, primeiramente, os custos para depois considerarem os clientes ou os concorrentes, outras começam considerando os preços para os clientes e dos concorrentes, para depois, observarem os custos. Esta é a base da filosofia do Sistema do Custeio Alvo.

Antes de adentrar ao tema, cabe comentar que, na pesquisa bibliográfica, percebeu-se que, enquanto alguns autores utilizam o termo "target costing", outros, citam "target cost", valendo, então, uma distinção. target costing (custeio-meta ou custeio-alvo) é o sistema de custeamento ou gerenciamento; enquanto que apurar o target cost (custo-meta ou custo-alvo) é o objetivo principal do referido sistema. Para efeito deste trabalho, os dois termos foram utilizados, nesse contexto. 
O Custeio-Alvo, segundo Feil, Kim e Yook (2004), surgiu na década de 1960, no Japão, tendo a engenharia de valor como base, sendo combinado com a idéia da redução de custos de produtos, durante as fases de pesquisa e desenvolvimento (P\&D) de um produto. Seu primeiro uso ocorreu em 1963, na Toyota, sendo denominado genka kikaku. Kato (1993) comenta que este termo, a partir do encontro anual da Sociedade de Custo do Japão em 1995, passou a ser considerado como "gerenciamento de custo-alvo". Este foco de gestão de custos é corroborado por Cooper e Chew (1996), Ansari (1997) e Cooper e Slagmulder (1997).

Sakurai (1997) entende o Custeio-Alvo como um sistema de gerenciamento estratégico desenvolvido para reduzir o custo, nos estágios de planejamento e desenho do produto. Os objetivos principais, segundo este autor, são: reduzir os gastos totais (incluindo custos de produção, despesas, tributos etc.), mantendo, ao mesmo tempo, alta qualidade, e planejar estrategicamente os lucros. Na opinião de Cooper e Slagmulder (1997), este método tem três grandes características: a) os custos são determinados ou permitidos pelo mercado; b) deve haver integração da empresa como um todo, visando a atingir os custos permissíveis; c) os custos e lucros são planejados para o longo prazo.

Hansen e Mowen (2003, p. 659) definem o Custeio-Alvo como um sistema utilizado para a determinação do custo de produtos e serviços, baseados no preço que os clientes estejam dispostos a pagar. A área comercial define as características e preços para o produto ou serviço, que sejam aceitáveis pelos clientes. A partir daí, a área de Pesquisa e Desenvolvimento irá projetá-lo e desenvolvê-lo, buscando que o preço possa cobrir os custos e despesas e, ainda gere lucro.

Atkinson et al. (2000, p. 679) afirmam que Custeio-Alvo é um "sistema de planejamento usado durante o ciclo de Pesquisa e Desenvolvimento, que enfoca os produtos que requerem processos discretos de fabricação e com um ciclo de vida razoavelmente curto." Para Monden (1999, p. 27), o Custeio-Alvo incorpora a gestão do lucro em toda empresa durante a etapa de desenvolvimento do produto, sendo que, seu processo, inicia-se com um planejamento geral do lucro no médio e longo prazo. Dessa maneira, pode-se tratar o CustoAlvo como sendo "o maior custo que se pode incorrer em um produto ou serviço, considerando-se que o mercado oferece o preço de venda, e os gestores determinam a margem de lucro, ou rentabilidade, esperada" (CREPALDI, 2004, p. 258).

Na realidade, quem determina o preço de venda é o mercado, e a partir desse preço, exclui-se uma margem de lucro desejada, e o que sobrar é o custo máximo que a empresa deverá perseguir, eliminando todos os possíveis desperdícios. Essa rubrica "custo máximo" contempla os tributos incidentes sobre vendas e resultados, os custos de produção e as despesas, sejam estas administrativas, comerciais ou financeiras; portanto, para se apurar o Custo Alvo, tem-se:

\section{Preço de Venda - Margem de Lucro Desejada = Custo Máximo (ALVO)}

Entende-se, portanto, que o Custo-Alvo é o maior custo que se deveria incorrer nas atividades de produção, comercialização, distribuição e gestão de um produto ou serviço. Cogan (1999) corrobora com a filosofia contida nesse método, e comenta que a melhor maneira de reduzir custos é implementar o Custeio-Alvo no estágio de projeto do produto. Para Machado (2002, p. 45), o custeio-alvo substituiu a pergunta "Quanto custa um produto?", pela pergunta, "Quanto deve um produto custar?".

O Custeio-Alvo direciona-se mais intensamente para a etapa de concepção e desenvolvimento (projeto) do produto, momento no qual, encontram-se as maiores 
possibilidades de mudança na estrutura de custos do mesmo. O principal objetivo é determinar se é possível produzir mais barato, mais rapidamente, com melhor margem e com maior qualidade. frente a produtos similares disponibilizados pela concorrência. Crepaldi (2004, p. 262), comenta que o Custeio-Alvo busca reduzir os custos na fase da pesquisa e desenvolvimento, desenho até a fabricação do produto. $O$ custo passa a ser uma meta a ser atingida pelas pessoas das áreas correlatas a essas operações. Caso esta meta não seja atingida, a administração reverá a viabilidade deste produto.

A coordenação de esforços conjuntos da empresa é mais uma importante característica. Com a implantação do custeio-alvo, os custos devem ser gerenciados por equipes multifuncionais, e que envolve a participação de toda a empresa. Enquanto na abordagem tradicional de custos, os mesmos são monitorados pelos contadores e profissionais ligados à área de custos; no custeio-alvo deve haver o envolvimento de outras diversas áreas, tais como: marketing (que, com base em pesquisas de mercado e identificação do valor percebido pelo consumidor, estabelece um preço-alvo para o produto); administração e finanças (que, mediante este preço-alvo, determina a margem-alvo que o produto deve oferecer) e a engenharia de produto (que deverá buscar minimizar o custo, até o mesmo ficar enquadrado dentro do custo-alvo). Todas estas atividades exigem um trabalho conjunto e de muita dedicação de toda a empresa para se atingir o custo-alvo desejado.

Seus principais objetivos concentram-se na redução de gastos totais com a manutenção da elevada qualidade do produto; em planejar estrategicamente os lucros, integrando informações de marketing/vendas com fatores de compras, engenharia, produção etc; bem como em fornecer suporte a decisões de ser ou não válido entrar no mercado, ou mesmo, de manter-se um produto no mercado (YU-LEE, 2002).

Monden (1999, p. 28), ao comentar os objetivos do Sistema do Custeio-Alvo, afirma que os mesmos resumem-se, de maneira geral, em dois principais: reduzir os custos de novos produtos, de maneira que o nível de lucro requerido possa ser garantido, ao mesmo tempo e que novos produtos satisfaçam os níveis de qualidade, tempo de entrega e preço exigidos pelo mercado; e motivar todos os funcionários a alcançar o lucro-alvo durante o desenvolvimento de novos produtos, tornando este "alvo" uma atividade de gestão do lucro por toda a empresa. Os gestores devem ser capazes de produzir oportunidades para alcançar eficiência em nível operacional, e melhorar os resultados econômico-financeiros por meio destas ações (YU-LEE, 2002).

Entende-se que, aqui reside uma das maiores dificuldades dos empreendedores das EPP's, pois há dificuldade em identificar, mensurar e controlar adequadamente os gastos de seu empreendimento. Cabe entender, por exemplo, que os gastos fixos, ocorrerão com ou sem produção, com ou sem vendas. Independentemente da quantidade produzida e vendida, a empresa deverá arcar com gastos do tipo aluguel, água, energia elétrica, telefone, salários e encargos, depreciações, dentre outros, para que a empresa possa desempenhar as suas atividades dentro de uma normalidade.

Para Yip (1996), a redução de gastos (custos e despesas) pode ser aplicada das seguintes maneiras: aumentar os benefícios de economias de escala; explorar o fator mais baixo de custos pela transferência de produção ou de outras atividades para locais de custo baixo; explorar a flexibilidade e realçar o poder de negociação (com fornecedores, trabalhadores e governo). A economia de escala, o aprendizado e a experiência, a eficiência nas fontes de suprimento, a logística favorável, as diferenças de custos e de habilidades do local em que a empresa está implantada e os custos de $\mathrm{P} \& \mathrm{D}$ do produto são os principais impulsionadores de custos que afetam os resultados econômicos do negócio. 
Diante desse contexto, considera-se que, ao empreender, os empreendedores de micro e pequenos negócios necessitam gerir os gastos (custos e despesas), assim como os resultados de sua empresa. A falta de gestão sobre estes gastos e resultados pode trazer grandes riscos ao empreendimento. O custo, por si só, não determina o preço, mas é um componente de suma importância para avaliar os impactos econômico-financeiros de suas decisões, bem como seu posicionamento competitivo em seu segmento de atuação. O CusteioAlvo pode vir a ser considerado como um instrumento útil e inovador nessa gestão.

No intuito de verificar a aplicabilidade do referido sistema de custeio na gestão dos micro e pequenos negócios, foi desenvolvida uma Pesquisa-Ação em uma pequena empresa do segmento de plásticos. Na seqüência, serão comentados os aspectos metodológicos empregados nesta pesquisa.

\section{ASPECTOS METODOLÓGICOS}

Esta pesquisa empregou como metodologia a Pesquisa Bibliográfica e uma PesquisaAção. Recorre-se, inicialmente à pesquisa bibliográfica no sentido de identificar os subsídios necessários a responder a questão norteadora e buscar o arcabouço para atender ao objetivo deste trabalho.

Ao aplicar-se o Sistema do Custeio-Alvo em uma pequena empresa cujas características básicas atenderam ao foco da implementação do instrumento, visando a validálo em situação prática, a metodologia de pesquisa estudada e entendida como a mais adequada foi a Pesquisa-Ação. Thiollent (2000, p. 14) considera esta metodologia como um tipo de pesquisa fundamentada empiricamente, e realizada em associação com ações ou resoluções de problemas coletivos, e em que os atores da situação e os pesquisadores, estejam envolvidos de maneira participativa e cooperativamente.

Na opinião de Martins (2006, p. 47), a Pesquisa-Ação (PA) consiste em unir ação e pesquisa em um processo em que, os atores envolvidos na situação participam com o pesquisador; de forma que consigam elucidar uma questão da realidade em que estão envolvidos, conseguindo identificar problemas, buscando e testando soluções em alguma situação real. Este autor considera que, dessa maneira, há produção e uso de conhecimento.

Para desenvolver a referida pesquisa, buscou-se alguma pequena empresa que fosse administrada por empreendedores que, com foco na melhoria da gestão de seus custos e resultados econômicos, concordassem em envolver-se ativamente na pesquisa, de modo cooperativo e participativo, tal como preconiza a filosofia da Pesquisa-Ação. Com este foco em mente, identificou-se em um município da Grande São Paulo, considerado pólo de referência na atuação do ramo plástico, uma empresa de pequeno porte (EPP), cujas características de produção, comercialização, distribuição, tributação e necessidades de novos métodos de gestão, adequaram-se à proposta de análise da utilidade e inovação do sistema de custeio estudado na gestão do pequeno negócio.

No contato inicial realizado com seus sócios-proprietários em janeiro de 2007, os mesmos demonstraram relevante interesse em ter acesso a novos instrumentos para a gestão de seu negócio, e entenderam ser a área de custos um dos pontos fundamentais a serem aprimorados em sua empresa.

Neste sentido, foi permitido o acesso a diversas informações de suas operações, sendo que, algumas destas, foram fornecidas por estes agentes, enquanto que outras foram obtidas junto ao Escritório de Contabilidade, prestador de serviços à empresa. As informações buscadas e analisadas foram: estrutura de custos dos produtos analisados (quantidades e valores de materiais; tempos de mão-de-obra e valores de salários, encargos e benefícios e custos indiretos das operações); preços de mercado; faturamentos de cada produto, 
tributações, despesas da empresa etc.

Para a aplicação do Custo Alvo, seguiu-se a lógica conceitual descrita no tópico 3 deste estudo. A pesquisa que teve o envolvimento dos pesquisadores e dos gestores da empresa, foi desenvolvida durante 60 dias. Por solicitação de seus empreendedores, a empresa estudada, sempre que mencionada será chamada de "Empresa Alfa".

\section{A APLICAÇÃO DO CUSTEIO-ALVO NA PEQUENA EMPRESA ALFA DO SEGMENTO DE PLÁSTICOS}

No mercado desde 1999, a "Empresa Alfa" atua no segmento de Plásticos, no ramo de recortados em Poliestireno Expandido - EPS (isopor), fornecendo seus produtos, principalmente, para a construção civil e, também, para o mercado de isolamento térmico e acústico. Instalada em uma área de $1.200 \mathrm{~m}^{2}$, possui como missão o fornecimento de placas e recortados em EPS aos seus clientes, proporcionando-lhes plena satisfação. O EPS ou isopor, que é a sua marca registrada, faz parte da vida das pessoas há muitos anos. Nas geladeiras portáteis, nas embalagens, nos trabalhos escolares e num sem número de aplicações, o EPS reafirma o seu papel de isolante térmico, fragilidade e leveza.

A empresa possui os seguintes produtos: telhas térmicas destinadas à construção civil; painéis para isolamento térmico e acústico; caixas térmicas para conservação de alimentos, bebidas e vacinas; e placas de EPS para distribuição em papelarias. Ressalta-se que a comercialização das Isotelhas (telhas térmicas) e das Placas Isotérmicas representaram, no primeiro semestre de 2007, em média, $91,3 \%$ de todo o seu faturamento. A empresa apresentou um faturamento médio de todos os produtos (de Janeiro/07 a Junho/07) no valor de $\mathrm{R} \$ 239.752,00$.

Analisando a linha de produção da empresa, chegou-se à conclusão de que o fluxo operacional dos produtos fabricados é composto por etapas produtivas que se resumem em: Carregar os blocos de EPS até o pantógrafo (máquina utilizada no processo produtivo); Posicioná-los no pantógrafo para que sejam recortados adequadamente; Programar o pantógrafo para efetuar o recorte; Recortar o EPS; Verificar a qualidade do produto acabado e Embalar.

A empresa conta com dois principais fornecedores, sendo um deles, responsável por $80 \%$ da matéria-prima consumida. Sua carteira de clientes é composta por, aproximadamente, trinta empresas. Das empresas mencionadas pelos sócios, cinco destacam-se na participação de seu faturamento, e estas, ou atuam na área da construção civil ou na de refrigeração.

No que diz respeito à gestão financeira, capta recursos no mercado financeiro, o equivalente, em média, a $53 \%$ de seu faturamento por meio de ações de descontos de títulos realizadas em bancos com quem mantém relacionamento. Isto implica na incidência de encargos financeiros mensais, em torno de 2,2\% do faturamento. Em termos tributários, classificava-se como empresa de pequeno porte (EPP) tomando-se por base o seu enquadramento no SIMPLES, e sua alíquota no mês de junho/07 foi de 7,5\% sobre o seu faturamento, incluídos, neste percentual, $0,5 \%$ de acréscimo por tratar-se de uma empresa industrial. A empresa está exposta à tributação do ICMS e do IPI sobre as compras de matéria-prima e materiais de embalagem, e de ICMS sobre suas vendas. A partir de Julho de 2007, houve alterações do sistema tributário SIMPLES para o SIMPLES NACIONAL, que não estão contempladas neste trabalho, pois o mesmo foi realizado antes desse período. As alterações só teriam impacto significativo neste trabalho, caso a empresa tivesse mudado do sistema tributário SIMPLES para o enquadramento no sistema do LUCRO REAL, o que não ocorreu. 
A empresa atua com onze funcionários com salários totais (inclusive encargos) de $\mathrm{R} \$$ 10.852,00, além de seus dois sócios, e encontram-se assim distribuídos: três estão alocados na área administrativa (salários totais de $\mathrm{R} \$ 3.560,00$ ); oito estão alocados na área de produção (salários totais de R \$ 7.292,00); e seus dois sócios, que atuam diretamente no negócio da empresa, fazem retiradas mensais de $\mathrm{R} \$ 5.000,00$, cada um, a título de pró-labore. Na Tabela 1 serão evidenciados os gastos fixos mensais desta empresa:

\begin{tabular}{|c|c|c|c|}
\hline Gastos & Valores em RS & $\%$ & Classificação \\
\hline $\begin{array}{l}\text { Salários Adm. + } \\
\text { Pró-Labore }\end{array}$ & 13.560 & 32,5 & Despesa Administrativa \\
\hline Telefone & 3.605 & 8,6 & Despesa Comercial \\
\hline Frete sobre Vendas & 8.320 & 20,0 & Despesa Comercial \\
\hline Juros pagos a bancos & 4.803 & 11,5 & Despesa Financeira \\
\hline $\begin{array}{l}\text { Salários da Fábrica } \\
\text { (MOD + MOI) }\end{array}$ & 7.292 & 17,5 & $\begin{array}{l}\text { Custos de Fabricação } \\
\text { (Diretos e Indiretos) }\end{array}$ \\
\hline Aluguel & 1.800 & 4,3 & $\begin{array}{l}\text { Custos Indiretos de } \\
\text { Fabricação }\end{array}$ \\
\hline $\begin{array}{l}\text { Depreciação Máquinas / } \\
\text { Equipamentos }\end{array}$ & 417 & 1,0 & $\begin{array}{l}\text { Custos Indiretos de } \\
\text { Fabricação }\end{array}$ \\
\hline Água & 262 & 0,6 & $\begin{array}{l}\text { Custos Indiretos de } \\
\text { Fabricação }\end{array}$ \\
\hline Energia Elétrica & 1.120 & 2,7 & $\begin{array}{l}\text { Custos Indiretos de } \\
\text { Fabricação }\end{array}$ \\
\hline Manutenção & 200 & 0,5 & $\begin{array}{l}\text { Custos Indiretos de } \\
\text { Fabricação }\end{array}$ \\
\hline Segurança & 180 & 0,4 & $\begin{array}{l}\text { Custos Indiretos de } \\
\text { Fabricação }\end{array}$ \\
\hline Materiais de Limpeza & 131 & 0,3 & $\begin{array}{l}\text { Custos Indiretos de } \\
\text { Fabricação }\end{array}$ \\
\hline $\begin{array}{l}\text { Total Gastos Fixos } \\
\text { (Custos e Despesas) }\end{array}$ & 41.690 & 100,0 & \\
\hline
\end{tabular}

Tabela 1 - Gastos Fixos da Empresa Alfa

Fonte: Dados da Pesquisa (2007)

Os gastos fixos totalizaram $\mathrm{R} \$ 41.690$, representando $17,4 \%$ do faturamento médio de $\mathrm{R} \$ 239.752,00$, citado anteriormente. Destes gastos, o maior é com salários, sejam estes administrativos ou da fábrica, equivalentes a $50 \%$ dos gastos totais. Outros gastos significativos são com fretes sobre vendas (20\%) e juros pagos a bancos (11,5\%). Outra informação relevante apurada em outra análise foi a do faturamento por produto. Como já comentado, de todos os seus produtos, apenas dois deles, a Isotelha $(55,9 \%)$ e a Placa Isotérmica $(35,4 \%)$, representam juntos $91,3 \%$ de seu faturamento, portanto, a aplicação do Sistema do Custeio Alvo, tomou por base estes dois produtos. Assim, considerando o faturamento total apenas destes dois produtos, que totaliza $\mathrm{R} \$ 218.894$, tem-se:

Faturamento da Isotelha $=\mathrm{R} \$ 133.936$ (participação de 61,2\%)

Faturamento da Placa Isotérmica $=\mathrm{R} \$ 84.958$ (participação de 38,8\%)

Com a disponibilidade destas informações, bem como das informações da estrutura de custos de cada produto (matéria-prima, embalagem, mão-de-obra direta e custos indiretos de fabricação), e visando a possibilitar aos empreendedores desta pequena empresa, não somente a detecção dos resultados obtidos por seus produtos, em determinado momento, mas também, 
uma análise antecipada e prospectiva; aplicou-se o Sistema do Custeio Alvo para a gestão dos custos e resultados dos produtos supracitados, já que não havia novos produtos em fase de pesquisa e desenvolvimento (P\&D).

\subsection{Apuração do Custo-Alvo dos Produtos Plásticos}

Para a apuração do Custo-Alvo, partiu-se dos preços de venda unitários, praticados no mercado, que foram estabelecidos pelos empreendedores para a venda de seus produtos; muitas vezes, levando em consideração o preço praticado pela concorrência. Além disso, foi considerada a quantidade média mensal, efetivamente negociada. Caso a análise fosse feita na fase de $\mathrm{P} \& \mathrm{D}$, deveria ser utilizada a quantidade prevista, numa análise prospectiva, considerada aceitável em termos de mercado. O preço de venda unitário multiplicado pela quantidade vendida, irá gerar a receita bruta de vendas (Faturamento Bruto), proveniente da negociação de um determinado produto.

Na seqüência, o empreendedor deve definir a Margem de Lucro Desejada, que é um percentual estabelecido pelo empresário com base na expectativa de retorno para o seu negócio. Nesta pequena empresa, os empreendedores definiram que desejam um lucro líquido de 10\% sobre as operações realizadas. Com essas informações disponíveis, já é possível apurar o Custo Alvo dos produtos da Empresa Alfa, tal como se pode observar na Tabela 2, a seguir:

\begin{tabular}{|c|c|c|c|}
\hline Descrição & TOTAL & ISOTELHA & PLACA \\
\hline Preço de Venda (unitário) & & $\mathrm{R} \$ 6,38$ & $\overline{\mathrm{R} \$ 4,83}$ \\
\hline Quantidade Mensal (peças) & & 20.993 & 17.590 \\
\hline Faturamento Bruto à Vista & R\$ 218.894 & R\$ 133.936 & R\$ 84.958 \\
\hline Margem de Lucro Desejada (10\%) & R\$ 21.890 & R\$ 13.394 & R\$ 8.496 \\
\hline (=) CUSTO ALVO & R\$ 197.004 & R\$ 120.542 & R\$ 76.462 \\
\hline
\end{tabular}

Considerando os Faturamentos Brutos à vista dos produtos Isotelha e Placa Isotérmica, reduzidos da margem desejada de $10 \%$, deveriam ter custos máximos (alvos) de R\$ 120.542 e R\$ 76.462, respectivamente. Diferentemente da fase de PeD, em que toda a empresa deveria buscar reduzir custos, antes até de os produtos entrarem em operação, como os produtos da Empresa Alfa, que já estão sendo comercializados no mercado; optou-se por apurar os Gastos Atuais da Empresa, por Produto, visando a apurar os valores que a empresa deveria reduzir para atingir os alvos supracitados na Tabela 2.

Portanto, nesta segunda etapa, foram levados em consideração todos os gastos (custos e despesas) incorridos nas operações de produção e comercialização dos produtos, bem como as despesas administrativas e financeiras incorridas pela empresa. Os percentuais dos Tributos incidentes sobre vendas foram obtidos com o contador terceirizado da empresa. As Despesas atuais foram obtidas com base nos controles gerenciais dos sócio-empreendedores. Estes, também possuíam controles dos consumos de matérias-primas, embalagens, mão-de-obra direta e custos indiretos de fabricação, mas não por produto. Na Tabela 3, podem ser vistos os gastos totais por produto, bem como o valor a ser reduzido, por produto, para atingir ao Custo-Alvo, que constam na Tabela 2. 


\begin{tabular}{|c|c|c|c|c|}
\hline \multicolumn{2}{|c|}{ COMPOSIČ̃̃O DOS GASTOS ATUAIS } & TOTAL & ISOTELHA & $\underline{\text { PLACA }}$ \\
\hline Tributos Incidentes s/Vendas ( $T$ ) & $\underline{25,5 \%}$ & $\underline{\text { RS } 55.817}$ & $\underline{\text { R\$ 34.153 }}$ & $\underline{\mathrm{R} \$ 21.664}$ \\
\hline SIMPLES & $7,5 \%$ & $\mathrm{R} \$ 16.417$ & $\mathrm{R} \$ 10.045$ & $\mathrm{R} \$ 6.372$ \\
\hline ICMS & $18,0 \%$ & $\mathrm{R} \$ 39.400$ & $\mathrm{R} \$ 24.108$ & $\mathrm{R} \$ 15.292$ \\
\hline Despesas Atuais (D) & $\underline{13,8 \%}$ & $\underline{\mathrm{R} \$ 30.288}$ & $\underline{R} \$ 18.531$ & $\underline{\text { R\$ } 11.757}$ \\
\hline Frete sobre Vendas & $3,8 \%$ & $\mathrm{R} \$ 8.320$ & $\mathrm{R} \$ 5.092$ & $\mathrm{R} \$ 3.228$ \\
\hline Despesas Administrativas & $6,2 \%$ & $\mathrm{R} \$ 13.560$ & $\mathrm{R} \$ 8.296$ & $\mathrm{R} \$ 5.264$ \\
\hline Despesas Comerciais & $1,6 \%$ & $\mathrm{R} \$ 3.605$ & $\mathrm{R} \$ 2.206$ & $\mathrm{R} \$ 1.399$ \\
\hline Despesas Financeiras & $2,2 \%$ & $\mathrm{R} \$ 4.803$ & $\mathrm{R} \$ 2.937$ & $\mathrm{R} \$ 1.866$ \\
\hline Custos dos produtos (C) & $\underline{51,9 \%}$ & $\underline{R} \$ 113.682$ & $\underline{\mathrm{R} \$ 69.277}$ & $\underline{\mathrm{R} \$ 44.405}$ \\
\hline A - Matéria-prima & $42,2 \%$ & $\mathrm{R} \$ 92.327$ & $\mathrm{R} \$ 55.212$ & $\mathrm{R} \$ 37.115$ \\
\hline B - Embalagem & $5,6 \%$ & $\mathrm{R} \$ 12.267$ & $\mathrm{R} \$ 8.397$ & $\mathrm{R} \$ 3.870$ \\
\hline $\mathrm{C}-\mathrm{MOD}+\mathrm{CIF}$ & $4,1 \%$ & $\mathrm{R} \$ 9.088$ & $\mathrm{R} \$ 5.668$ & $\mathrm{R} \$ 3.420$ \\
\hline GASTOS ATUAIS $(T+D+C)$ & $91,2 \%$ & R\$ 199.787 & R\$ 121.961 & R\$ 77.826 \\
\hline CUSTO ALVO & $90,0 \%$ & R\$ 197.004 & R\$ 120.542 & $\mathrm{R} \$ 76.462$ \\
\hline REDUÇÃO PARA ATINGIR AL & $1,2 \%$ & R\$ 2.783 & R\$ 1.419 & R\$ 1.364 \\
\hline
\end{tabular}

Tabela 3 - Composição dos Gastos Atuais e Redução para atingir o Alvo.

Fonte: Dados da Pesquisa (2007)

Cabe ressaltar que, como a empresa enquadra-se no regime de tributação SIMPLES NACIONAL, não foram tratadas as questões de possíveis créditos de ICMS. Focalizados no objetivo desta Pesquisa-ação, foram desenvolvidos controles de custos por produto, com base nas quantidades consumidas, nos tempos incorridos em cada etapa do processo produtivo, nos custos unitários das matérias-primas, bem como da mão-de-obra direta e dos custos indiretos de fabricação de cada produto. Estes controles não estão sendo evidenciados por não ser o foco deste trabalho, mas ultrapassaram as expectativas dos sócio-empreendedores que estavam participando ativamente da pesquisa.

Observa-se na Tabela 3 que os gastos atuais da empresa representam 91,2\% do Faturamento Bruto. A necessidade de redução para se atingir o Alvo é uma informação considerada como item estratégico para os empreendedores. O seu valor pode apresentar-se positivo, negativo ou nulo (zerado). Na Tabela 3, ambos os produtos apresentaram valores positivos, o que denota que há valor a ser reduzido, em comparação com dos Gastos Totais Atuais com o Custo Alvo. Por exemplo, o valor total de R $\$ 2.783$ reflete que os gastos totais atuais da empresa para os dois produtos são maiores que o Custo-Alvo neste montante; sendo $\mathrm{R} \$ 1.419$ no produto Isotelhas e R \$ 1.364 nas Placas Isotérmicas.

Esta informação de redução indica que algo deve ser revisto na produção e comercialização dos produtos, e denota uma sinalização da necessidade de rever detalhadamente, item por item da composição dos gastos (custos e despesas) de cada produto, visando a identificar possibilidades de obtenção de redução de custos; de redução das despesas consideradas gerenciáveis pelo empreendedor; de redução da expectativa de margem de remuneração esperada; ou ainda, da implementação de algumas destas alternativas, ou de todas, conjuntamente.

Por exemplo, o mais forte componente do custo do produto é a Matéria-Prima 
(42,2\% do faturamento); mas, tendo o EPS origem no ramo petroquímico, há certa dificuldade de negociação com seus fornecedores; fato comprovado pelos gestores da Empresa Alfa, e que, também ocorre para as Embalagens (5,6\%). Os custos com Mão-de-Obra Direta (MOD) e Custos Indiretos de Fabricação (CIF), proporcionalmente, pouco representam em corte de custos $(4,1 \%$ do faturamento), por já estarem ajustados às necessidades da empresa. Caso haja maior aprofundamento na análise destes custos pelo Método do Custeio Baseado em Atividades, que não foi tratado por este trabalho, alguns desperdícios poderão ser identificados.

Portanto, caso estes custos-alvos não sejam atingidos, os empreendedores desta pequena empresa têm quatro principais possibilidades de ação: (a) envidar os máximos esforços para a obtenção de redução dos custos dos produtos; (b) atuar na redução das despesas consideradas gerenciáveis pelo empreendedor; (c) aceitar reduzir a margem de remuneração esperada; (d) ou utilizar algumas destas alternativas, ou todas, conjuntamente.

Pelo exposto, a situação atual apresentada nesta análise, não há muitas alternativas de redução de custos; e não sendo possível alterar as alíquotas dos tributos, resta buscar redução nas despesas administrativas, comerciais e financeiras. Caso a implementação destas alternativas não seja considerada possível pelos sócio-empreendedores, e o instrumento proposto possibilite e facilite esta análise, há de repensar-se os processos de suprimentos, produção, comercialização e distribuição dos produtos em questão, sob pena de obter resultados pouco satisfatórios.

Assim, entende-se que o Sistema do Custeio-Alvo, sendo aplicado a produtos que já estão em operação, possibilita a identificação da viabilidade ou não da produção e comercialização de determinado produto ao mercado consumidor, inclusive, sob uma análise prospectiva. Nitidamente, por esta análise, buscando atingir o Custo-Alvo, e tendo em mente a não alteração do preço do produto no mercado; a Empresa Alfa possui como principal alternativa, diante do atual contexto, a redução da margem de lucro esperada (10\%) para os atuais $8,7 \%$ de margem líquida apurados atualmente, a partir da subtração dos gastos atuais de R \$ 199.787 (vide Tabela 3), da receita bruta de R 218.894 (vide Tabela 2), em relação a esta receita.

As informações apuradas a partir da aplicação do Sistema do Custeio-Alvo, desenvolvidas com base na Pesquisa-Ação conjunta com os sócio-empreendedores da Empresa Alfa, foram consideradas por estes como úteis e oportunas, pois são de fácil apuração e interpretação, e de caráter inovador e estratégico à gestão do pequeno negócio.

\subsection{Vantagens e Limitações da Apuração do Custo-Alvo}

Diante do desenvolvimento da Pesquisa-Ação, focalizada na inovação do instrumento - Sistema do Custeio Alvo, e sua utilidade para os pequenos negócios; em conjunto com os sócio-empreendedores da Empresa Alfa, os pesquisadores reconheceram algumas vantagens, a saber:

a) é um instrumento que permite ao empreendedor atuar, não somente na detecção do problema no dia-a-dia, mas também atuar no sentido da prevenção, em razão de que o mesmo poderá simular os impactos causados por alterações nos valores da matéria-prima, folha de pagamento, tributação, junto aos resultados dos produtos e sobre o negócio. Poderá simular, mediante dados estimados, a viabilidade do lançamento de um novo produto ou, até mesmo, da implementação de um novo negócio;

b) o instrumento parte de uma das principais certezas de que o pequeno empresário possui, ou seja, o valor de mercado (preço) do bem que ele se propõe a produzir e 
comercializar, além ao volume praticado (ou estimado) de vendas;

c) deixa de lado o sistema tradicional de adicionar-se um mark-up ao custo estimado do produto para se chegar ao preço de venda (estratégia bastante utilizada pelos micro e pequenos empreendedores); para, trilhando o caminho inverso, partir do faturamento estimado da empresa (mediante um preço de venda estabelecido pelo mercado) e, após diminuir a margem de lucro desejada para a remuneração de seu investimento, apurar o custo máximo (alvo) que o produto possa ter para que seja produzido, dentro de uma perspectiva de equilíbrio financeiro. Dessa forma, permite verificar qual dos demais itens deverão ser ajustados, visando a suportar o Custo-Alvo do produto; ou então, caso isto não seja viável, passa-se a repensar a sua produção e comercialização, sob a pena da geração de resultados econômicos negativos;

d) o relatório permite, ainda, uma análise mais detalhada do que se denominou Custo-Alvo do produto, em razão da segregação do mesmo em partes fundamentais, que contemplam custos e despesas, ou seja, tributos incidentes sobre vendas, custos com matériasprimas, embalagens, mão-de-obra direta, custos gerais de fabricação, despesas administrativas, comerciais e financeiras, e

e) é um instrumento inovador e de fácil utilização pelo empreendedor, em que se pode gerar um relatório sintético com as principais informações necessárias acerca da composição dos preços, gastos (custos e despesas) e resultados de um produto, e que irá auxiliar o empreendedor na potencialização de suas habilidades e conhecimentos do sobre o seu segmento de atuação.

Dentre as limitações identificadas, ressaltam-se:

a) requer, por parte do empreendedor, um estudo detalhado do produto a ser fabricado no que diz respeito a quantidades, pesos, medidas, perdas, tempos e métodos produtivos, tipo de máquinas utilizadas na produção, capacidade instalada, produção horária, limitação dos equipamentos etc., principalmente para gerar informações dos custos de cada produto;

b) nem sempre as MPE's dispõem de gestores que tenham conhecimentos sobre a identificação, mensuração e controle de custos, ou que tenham interesse por desenvolver relatórios que gerem esta informação, e

c) os dados utilizados para a geração das informações devem ser os mais realistas possíveis, e nem sempre há esse controle econômico-financeiro por parte das micro e pequenas empresas.

Após o desenvolvimento desta Pesquisa-Ação, na sequência, serão desenvolvidas as considerações finais deste trabalho.

\section{CONSIDERAÇÕES FINAIS}

Este trabalho enfatizou o perfil do empreendedor e a situação atual da micro e pequena empresa (MPE) no Brasil. Nele, pôde-se identificar que o processo de gestão dos pequenos negócios encontra-se centralizado nas mãos do empreendedor. Este, por sua vez, na maioria das vezes, possui conhecimento do negócio, sem possuir as habilidades administrativas necessárias para a condução do mesmo. $\mathrm{O}$ empreendedor, levando em conta muito mais o seu "feeling" do que qualquer outro conhecimento técnico, no momento da tomada de decisão, pode comprometer o resultado econômico positivo (lucro) de seu negócio.

Detectado o problema "gestão" existente nas MPEs, delineou-se este trabalho para um assunto que impactasse diretamente a saúde econômico-financeira do pequeno empreendimento e que, se não bem administrado, tenderia a levá-lo para os caminhos da 
descontinuidade. A opção pela discussão sobre a necessidade de uma gestão de custos da empresa de pequeno porte, como tema central deste estudo, deve-se ao entendimento de que, carecendo de habilidades gerenciais, o pequeno empresário acaba por não fazê-la, ou quando a implementa, o faz, algumas vezes, de maneira incorreta.

A tentativa dos pequenos empresários em adaptarem-se aos preços sugeridos pelo mercado, sem nem mesmo entenderem como funcionam as estruturas de custos de suas empresas, faz com que muitos, sem perceber, caminhem a passos largos para a descontinuidade de seus negócios. Dessa forma, entende-se como importante, não somente discutir a implementação de uma gestão adequada dos custos da MPE, mas também sugerir um instrumento inovador que se pautasse na simplicidade do entendimento, visando a facilitar a sua utilização pelos gestores das MPE's.

Considerando como base o conceito contemplado pelo Sistema do Custeio-Alvo, em que o Custo-Alvo deve ser entendido como sendo o máximo custo que se pode incorrer em um produto, considerando-se que o mercado oferece o preço de venda aceitável, e que os gestores empreendedores determinam a margem de lucro ou a rentabilidade esperada. A fatia que sobra desta conta básica Preço menos Margem de Lucro Desejada é o Custo-Alvo.

Outra preocupação que sempre esteve ligada ao fato de que o sistema analisado neste estudo pudesse ser aplicado, não somente para a continuidade dos negócios; mas, também que pudesse servir como um instrumento prospectivo, atuando na prevenção, e possibilitando simulações de cenários; e, até mesmo, para que servisse como balizador para as análises do lançamento de novos produtos ou para o ingresso em novos negócios.

Ao mesmo tempo em que se pretendeu tratar do assunto MPE e das dificuldades na implementação da gestão de custos para estas empresas, entendeu-se por bem, não somente apresentar uma contribuição teórica, mas também prática, como forma de possibilitar ao empreendedor de empresas de pequeno porte, mais um instrumento inovador e facilitador para a gestão de seu negócio. Buscou-se, então, validá-lo, e foi neste contexto que surgiu a Empresa Alfa como grande apoiadora desta possibilidade. De maneira cooperativa e participativa, abriu suas portas e seus dados, no sentido de que a aplicação do Sistema do Custeio-Alvo pudesse refletir um diagnóstico o mais próximo possível da sua realidade.

Durante os diversos contatos com os sócio-empreendedores da referida empresa, ficou claro o perfil estudado acerca do empreendedor brasileiro: com muita vontade e determinação, conhecedor do ramo de negócio em que atua, porém desprovido de habilidades gerenciais, extremamente necessárias à continuidade e crescimento de seus negócios.

As informações apuradas a partir da aplicação do Sistema do Custeio-Alvo, desenvolvidas com base na Pesquisa-Ação desenvolvida em conjunto com os sócioempreendedores da Empresa Alfa, foram consideradas por estes como úteis e oportunas, pois são de fácil entendimento e apuração, e de caráter inovador e estratégico à gestão do pequeno negócio.

Importante frisar, neste momento, que a Pesquisa-Ação desenvolvida não é uma metodologia de pesquisa costumeiramente utilizada em produções científicas, e este trabalho não possui a pretensão de concluir que, apenas com a utilização do Sistema do Custeio-Alvo, a MPE pode garantir a continuidade e a prosperidade do negócio; pois isto, claramente, não seria possível. Este sistema pode ser considerado como mais um instrumento inovador, dentre outros vários que, se bem utilizados pelos empreendedores dos pequenos negócios, poderão fornecer informações úteis e oportunas, visando a balizar suas tomadas de decisões, normalmente, carentes de aspectos técnicos em termos econômico-financeiros.

Retomando a questão-problema levantada no início deste trabalho, o próprio desenvolvimento da pesquisa comprovou que o Sistema do Custeio-Alvo gera informações 
econômico-financeiras úteis e oportunas, e é um instrumento inovador para a gestão de custos e resultados do empreendedor de um pequeno negócio. A pesquisa realizada em apenas uma empresa pode até não permitir generalizações, mas denota a realidade da gestão de uma MPE, e confirma o que foi evidenciado por Bedê (2005), quando da pesquisa para o Sebrae, em relação aos conhecimentos do empreendedor e da gestão de MPE's.

Como recomendações para novos trabalhos, sugerem-se novas aplicações do Sistema do Custeio-Alvo em MPE's de outros segmentos, para comprovar e reiterar o que foi constatado nesta pesquisa, bem como a aplicação conjunta do Custeio-Alvo com o Custeio Kaizen que, segundo Monden (1999), tem como principal objetivo a constante busca de reduções de custo em todas as etapas do processo produtivo, para ajudar a eliminar qualquer diferença entre os lucros-alvo com os lucros obtidos, visando à melhoria contínua.

\section{REFERÊNCIAS}

ANSARI, S. et al. 1997. Target costing: the next frontier in strategic cost management. Consortiun for Advanced Manufacturing International. Bedford, Texas.

ATKINSON, A. A. et al. 2000. Contabilidade Gerencial. São Paulo: Atlas.

BEDÊ, M. A. (Coord.). 2005. Sobrevivência e mortalidade das empresas paulistas de 1 a 5 anos.Disponível: $<$ http://www.sebraesp.com.br/principal/conhecendo $\% 20 \mathrm{a} \% 20 \mathrm{mpe} / \mathrm{mortalida}$ de $\% 20 \mathrm{de} \% 20$ empresas/documento_de_mortalidade_de_empresas/sobrevivencia_mortalidade _empresas_paulistas_04_05.pdf> Acesso em: 17/06/2008.

BERNARDI, L. A. 2003. Manual de empreendedorismo e gestão - fundamentos, estratégias e dinâmicas. São Paulo: Atlas.

BERTÓ, D. J.; BEULKE, R. 2006. Gestão de Custos. São Paulo: Saraiva.

BRASIL. Lei Complementar $n^{\circ} 123$, de 14/12/2006. Lei Geral das Micro e Pequenas Empresas. Institui o Estatuto Nacional da Microempresa e da Empresa de Pequeno Porte; altera dispositivos das Leis $n^{\circ}$ s 8.212 e 8.213, ambas de 24 de julho de 1991, da Consolidação das Leis do Trabalho - CLT, aprovada pelo Decreto-Lei $n^{0} 5.452$, de $1^{\circ}$ de maio de 1943 , da Lei $\mathrm{n}^{\mathrm{o}}$ 10.189, de 14 de fevereiro de 2001, da Lei Complementar $\mathrm{n}^{\mathrm{o}}$ 63, de 11 de janeiro de 1990; e revoga as Leis $n^{\circ} \mathrm{s} 9.317$, de 5 de dezembro de 1996, e 9.841, de 5 de outubro de 1999.

CHER, R. 1991. A gerência das pequenas e médias empresas - o que saber para administrá-las. $2^{\text {a }}$. Ed. São Paulo: Maltese.

CHIAVENATO, I. 2006. Empreendedorismo: dando asas ao espírito empreendedor. São Paulo: Saraiva.

COGAN, S. 1999. Custos e preços: formação e análise. São Paulo: Pioneira.

COOPER, R; CHEW, W. B. 1996. Control tomorrow's costs through today's designs. Harvard Business Review. Vol. 74. No. 1. Jan./Feb, p.88-97.

; SLAGMULDER, R. 1997. Factors influencing the target costing process: 
lessons from japanese practice. Fev/1997, p.28. Disponível em:<www.feb.ugent.be/fac/research/wp/papers/up_97.30> Acesso em 14/09/2005.

CREPALDI, S. A. 2004. Contabilidade gerencial: teoria e prática. 3ª ed. São Paulo: Atlas.

DORNELAS, J. C. A. 2001. Empreendedorismo: transformando idéias em negócios. Rio de Janeiro: Campus.

DUBOIS, A.; KULPA, L.; SOUZA, L. E. 2006. Gestão de Custos e Formação de Preços Conceitos, modelos e instrumentos - Abordagem do Capital de Giro e da Margem de Competitividade. São Paulo: Atlas.

FEIL, P; KIM, I; YOOK, K. 2004. Japanese target costing: a historical perspective. International Journal of Strategic Cost Management. Spring, p. 10-19.

HANSEN, D. R.; MOWEN, M. M. 2003. Gestão de Custos - Contabilidade e Controle. São Paulo: Pioneira Thomson Learning.

HORNGREN, C. T.; DATAR, S. M.; FOSTER, G. 2004. Contabilidade de Custos - Uma Abordagem Gerencial. 11 a . ed. São Paulo: Pearson Prentice Hall.

KASSAI, S. As empresas de pequeno porte e a contabilidade. 1996. Dissertação (Mestrado em Controladoria e Contabilidade) Faculdade de Economia, Administração e Contabilidade da Universidade de São Paulo, São Paulo.

KATO, Y. 1993. Target costing support systems: lessons from leading Japanese companies. Management Accounting Research, Vol.4, p.33-47.

LONGENECKER, J. G. et al. 2003. Small Business Management: An Entrepreneurial Emphasis. 12a. Ed. Thompson/South Western.

MACHADO, D. J. 2002. Custeio-Meta Aplicado Estrategicamente em Empresas de Pequeno Porte: Estudo de Caso. Dissertação (Mestrado em Ciências Contábeis). Pontifícia Universidade Católica de São Paulo - PUC-SP, São Paulo..

MACHADO, J. R. 2005. Planejando a estratégia de pequenos negócios. Rio de Janeiro: Qualitymark.

MARTINS, G. de A. 2006. Estudo de Caso: uma estratégia de pesquisa. São Paulo: Atlas.

MATIAS, A. B.; LOPES JÚNIOR, F. 2002. Administração financeira nas empresas de pequeno porte. São Paulo: Manole.

MAXIMIANO, A. C. A. 2006. Administração para Empreendedores: fundamentos da criação e da gestão de novos negócios. São Paulo: Pearson Prentice Hall.

MONDEN, Y. 1999. Sistemas de Redução de Custos - Custo-Alvo e Custo Kaizen. Porto Alegre: Bookman. 
NECK, P. A. 2000. Desarollo de pequeñas empresas: políticas y programas. México: Limusa.

PINHEIRO, M. 1996. Gestão de desempenho das empresas de pequeno porte: uma abordagem conceitual e empírica. Tese (Doutorado em Administração). Faculdade de Economia, Administração e Contabilidade da Universidade de São Paulo, São Paulo.

SAKURAI, M. 1997. Gerenciamento integrado de custos. São Paulo: Atlas.

SMALL BUSINESS ADMINISTRATION - SBA. 2007. The Small Business Economy For Data Year 2006 - A Report to the President. Disponível em: $<$ http://www.sba.gov/advo/research/sb_econ2007.pdf $>$ Acesso em: 17/06/2008.

THIOLlent, M. 2000. Metodologia da Pesquisa-Ação. 11ª ed. São Paulo: Cortez.

YIP, G. S. 1996. Global Strategy... In a world of nations. In: MINTZBERG, H., QUINN, J. The strategy process: concepts, contexts and cases. $3^{\mathrm{a}}$. Ed. New Jersey: Prentice-Hall.

YU-LEE, R. T. 2002. Target costing: What you see is not what you get. Journal of Cost Management. July/August, p.23-28. 